\title{
The Nutritional Status of the Children with Severe- ECC Comparison with the Nutritional Status of Children without Caries Aged 3-5-Years-Old and with the Caregiver's Demographics in a Kenyan Hospital
}

\author{
Dorah Wassuna, Gladys Opinya*, Mary Masiga, Edith Ngatia and Regina Mutave \\ Department of Paediatric Dentistry, School of Dental Sciences, College of Health Sciences, University of Nairobi
}

Received: 篅April 13, 2018; Published: 眥April 27, 2018

*Corresponding author: Gladys Opinya, Department of Paediatric Dentistry \&Orthodontics; School of Dental Sciences; College of Health Sciences, University of Nairobi, P.O. Box 30197, Kenya

\begin{abstract}
Severe early childhood caries (Severe-ECC) is an aggressive, infectious and preventable form of dental caries that affects very young children. The survey purposed to examine any differences in the severity of poor nutrition in children without decay and those children with dental decay in the age group between thirty-six and sixty months. Sampling was purposeful and 196 children aged between 3 to 5 years for this study. The study was hospital-based where eighty-one children with severe dental decay who had attended the Nyanza Provincial General Hospital (NNPGH). Similarly, one hundred and fifteen children who were caries free were chosen from amongst the children attending the maternal child health clinic at NNPGH over a period of three months. Odds Ratio (OR) and 95\% Confidence Interval (CI) were used to estimate the strength of association between Severe ECC and nutritional status. The mean $\mathrm{dmft}$ for the children with severe Early Childhood Caries (ECC) was $7.5 \pm 19$. The prevalence of malnutrition was reported among both groups of children with severe ECC and without decay as 28 (14.3\%) underweight, wasting 5(2.5\%), and stunting $9(4.6 \%)$. The malnutrition in children with, Severe-ECC was observed as $27(14 \%)$ underweight; $10(4.9 \%)$ of the children were wasted, and $5(2.5 \%)$ were stunted. However among the children without caries $26(13.9 \%)$ were underweight while 5 (2.6\% were wasted, and $12(6.1 \%)$ were stunted. Both children those with severe ECC and those with decay, however, the children who were likely to be underweight at 1.23 times were those affected with severe ECC at 1.23 times compared to the children without decay. Hence other factors may be playing a role in malnutrition of children aged 3-5year old.
\end{abstract}

Keywords: Severe-ECC; Nutritional status; Caregivers demographics

\section{Introduction}

Early childhood caries (ECC) is defined as the presence of one or more decayed (non-cavitated or cavitated lesions), those missing (due to caries), or filled tooth surfaces in any primary tooth in a child 71 months of age or younger. Severe Early Childhood Caries reported in children below three years of age as smooth surface caries1. One or more cavitated, missing teeth due to caries has been associated with age s 3-5years.The filled smooth surfaces in primary maxillary anterior teeth or a decayed, missing or filled a score $\geq 4$ for age 3years, a score of $\geq$ five is associated with 4years while cavitation, restored tooth and missing due to caries a score of $\geq 6$ is for children in the 5-year-old group. All these scores constitute Severe - ECC [1].

Disadvantaged groups have been found to be vulnerable to ECC in both developed and developing countries and even within a single country disparity by social standing there exist, differences due to diet, fluoride use, and social empowerment. Disparities in social empowerment may persist due to lack of access to dental care and inadequate utilisation of dental care even when available [2]. Untreated caries and associated infections can cause pain, discomfort, reduced intake of foods because eating is painful 
[3]. Pain may also because the child refuses the caregiver from maintaining good oral hygiene for the child. There is a paucity of literature on the prevalence of Severe -ECC in Kenya. However, a study conducted in nursery school children in Nairobi on the on dental caries and dietary patterns reported a prevalence of $63.5 \%$ among 3-5 years old [4]. A survey conducted in Kiambaa division in Kiambu County, a peri-urban population, reported ECC prevalence in 3 - 5-year-olds of 59.5\% [5]. Several studies on nutritional status and dental caries have reported variable results. A retrospective survey on the body mass index was done in the United States of America, and it involved two hundred and ninety-three children aged two to five years with Severe - ECC receiving dental treatment under general anaesthesia. In the study, the weight groups were defined by being assigned the CDC body mass index about on age and gender of the children. Results showed that the distribution of subjects by percentiles and the children who were underweight were $11 \%$; of the study sample. However the children whose weight was normal weight $67 \%$; at risk of overweight $9 \%$; overweight $11 \%$. This study concluded that significantly, more children in the sample were underweight than in the reference population [6]. However comparative research on the nutritional status and dental caries among a large sample of four and five-year-old South African children found no significant association between the prevalence of caries and stunting or wasting. However, a relationship was found between decayed, missing and filled surfaces and wasting [7]. This study, therefore, aimed to compare the nutritional status of children aged $3-5$ years with Severe-ECC and the nutritional status of those aged 3-5 years without caries.

Severe ECC is also associated with oral Microbiota, and in particular anaerobic bacteria of the species Scardovia Wigggsiae and others have been found in abundance in severe ECC lesions [8]

\section{Materials and Methods}

One hundred and ninety-six children aged between 3 to 5 years were recruited for this study. Purposive sampling was done to select Eighty-one children with Severe - ECC was chosen from amongst the patients who had sought dental treatment at the dental clinic at the Nyanza Provincial General Hospital (NNPGH). However, 115 children who were caries free were selected from amongst the children attending the maternal child health clinic at NNPGH over a period of three months. Inclusion criteria were: the child was 3 - 5 years of age, was medically healthy, and the parent or caregiver was willing to consent. A semi-structured questionnaire was administered to the caregiver in a face to face interview, and information was collected on the socio-demographic background of the children. There gathered data included education level, age, gender, and the caregiver's, occupation, and area of residence of the caregivers. The Intraoral examination was carried using dental mirrors and a Michigan 0 dental probe under natural light as the child sat on an ordinary chair facing the light. Severe ECC was defined as decayed, missing or filled a score of $\geq 4$ (age 3), $\geq 5$ (age 4), $\geq 6$ (age 5). Before dental caries diagnosis, each tooth was dried using a piece of sterile gauze. WHO 1997 caries diagnosis criteria were used, and dental caries was diagnosed when there was a clinically detectable loss of tooth substance and when such damage had been treated with fillings or extraction [9]. Anthropometric measurements were determined to assess the nutritional status of the children and height of the children were obtained by measuring the child standing when standing erect and barefoot, using a measured with a standard height board to the nearest $0.5 \mathrm{~cm}$. Weight for age was measured using a Salter scale to the nearest $0.1 \mathrm{~kg}$. Each parameter of height and weight had three measurements taken, and an average of each was then recorded. The Cut-offs +2 standard deviations (SD) were used to identify children at significant risk for either delayed (<-2SD) or excessive ( $>+2 \mathrm{SD}$ ) growth. The indicators were weight-for-age (WAZ), height-for-weight (HAZ), weight-forheight (WHZ) based on the World Health Organisation(WHO) 2005 recommended reference standard [10]. The collected data collected were coded, cleaned and analysed using SPSS version 17.0 (SPSS Inc, Chicago Illinois, USA) for Windows and Microsoft Office Excel 2007. Nutritional data was analyzed using Epi-Nutri program of Epi-Info version 3.5.1. Descriptive statistics such as proportions were used to summarize categorical variables while measures of central tendency such as mean, standard deviations and ranges were used to summarise continuous variables. The strength of association was established between categorical values using a Pearson's Chi-square tests. Odds Ratio (OR) and 95\% Confidence Interval (CI) were used to estimate the strength of association between independent variables and the dependent variable. The multivariate analysis was done using binary logistic regression at a statistical significance set at $p \leq 0.05$. The relevant research and ethics approving institutions approved the study.

\section{Results}

A total of 196 children aged 3-5 years were recruited into the study, eighty-one children with S - ECC (41.3\%) and 115(58.7\%) without caries. The study group had a mean age of $4.1+0.6 y e a r s$, and it ranged from 3- 5 years with a high proportion of the children $(62.2 \%)$ aged four years. There was a statistically significant difference in age distribution among children with Severe ECC and children without caries $(\chi 2=28.36, \mathrm{~d} . \mathrm{f}=2, \mathrm{p}<0.001)$. The majority of the children with caries were aged four years (84.0\%) compared to those without caries (47.0\%).Gender distribution was comparable with boys slightly more $(51.0 \%)$ than girls $(49.0 \%)$.

Sixty-five children (33.2\%) lived in the rural community, and $131(66.8 \%)$ lived in the urban area. The differences in the area of residence were significant with a Pearson chi square=13.36, $\mathrm{df}=1, \mathrm{p} \leq 0.001$ ) for the children with severe ECC and those children without decay. It was noted that sixty-six (81.5\%) out of 81 children with Severe ECC lived in an urban setting when compared to children who were caries- free who had 65 (56.5\%) out of 115 children who were caries free. Some sixty-eight caregivers had had primary school education of whom 24 (29.6\% had severe ECC while $44(38.3 \%)$ ) were caries free. However, 103 caregivers had 
secondary school education of whom 43 (53.1\% had severe-ECC and60 (52.2\%), while $21(10.7 \%)$ their caregivers had tertiary education and $14(17.3 \%)$ and seven $6.1 \%$ were caries free. Also, children whose caregivers had a primary level of education had the highest prevalence of severe-ECC followed by those whose caregivers had secondary education. The differences in the severecares prevalence were significant with a Pearson Chi-square $=9.41$ d.f 3, p $\leq 0.024$ Table $1 \& 2$.

Table 1: Age and gender distribution of children with Severe - ECC and children without caries.

\begin{tabular}{|c|c|c|c|c|c|c|c|}
\hline \multirow{2}{*}{ Variables } & \multicolumn{2}{|c|}{ Total $n=196$} & \multicolumn{2}{|c|}{ Severe - ECC $n=81$} & \multicolumn{2}{|c|}{ Without caries $n=115$} & \multirow[t]{2}{*}{ Test of 1 significance $\leq 0.05 \chi 2$} \\
\hline & $\mathbf{n}$ & $\%$ & $\mathbf{n}$ & $\%$ & $\mathbf{n}$ & $\%$ & \\
\hline \multicolumn{8}{|c|}{ Age group } \\
\hline 3 years & 69 & 35.2 & 13 & 16.0 & 56 & 48.7 & \multirow{3}{*}{$\begin{array}{l}\text { Pearson Chi square 28.36, d.f } 2.00 \\
\text { p } \leq 0.001\end{array}$} \\
\hline 4 years & 122 & 62.2 & 68 & 84.0 & 54 & 47.0 & \\
\hline 5 years & 5 & 2.6 & 0 & 0.0 & 5 & 4.3 & \\
\hline \multicolumn{8}{|c|}{ Sex of child } \\
\hline Male & 100 & 51.0 & 43 & 53.1 & 57 & 49.6 & \multirow{2}{*}{$\begin{array}{l}\text { Pearson Chi square } 0.24 \text {, d.f1, } \\
\text { p }=0.627\end{array}$} \\
\hline Female & 96 & 49.0 & 38 & 46.9 & 58 & 50.4 & \\
\hline
\end{tabular}

Table 2: Level of education, demographics for the caregivers, place of residence, level of education, and occupation.

\begin{tabular}{|c|c|c|c|c|c|c|c|}
\hline \multirow{2}{*}{ Variables } & \multicolumn{2}{|c|}{ Total $n=196$} & \multicolumn{2}{|c|}{ Severe - ECC $\mathbf{n}=81$} & \multicolumn{2}{|c|}{ Without caries $n=115$} & \multirow[t]{2}{*}{ Test of statistical significance $p \leq 0.05$} \\
\hline & $\mathbf{n}$ & $\%$ & $\mathbf{n}$ & $\%$ & $\mathbf{n}$ & $\%$ & \\
\hline \multicolumn{8}{|c|}{ Place of residence } \\
\hline Rural & 65 & 33.2 & 15 & 18.5 & 50 & 43.5 & \multirow{2}{*}{ Pearson Chi square $=13.36$ d.f. $1, \mathrm{p}=0.001$} \\
\hline Urban & 131 & 66.8 & 66 & 81.5 & 65 & 56.5 & \\
\hline \multicolumn{8}{|c|}{ Caregiver's level of education } \\
\hline No formal education & 4 & 2.0 & 0 & 0.0 & 4 & 3.5 & \multirow{4}{*}{ Pearson Chi square $=9.41$ d.f $3, p=0.024$} \\
\hline Primary & 68 & 34.7 & 24 & 29.6 & 44 & 38.3 & \\
\hline Secondary & 103 & 52.6 & 43 & 53.1 & 60 & 52.2 & \\
\hline Higher education & 21 & 10.7 & 14 & 17.3 & 7 & 6.1 & \\
\hline \multicolumn{8}{|c|}{ Caregiver's occupation } \\
\hline Formal & 43 & 21.9 & 14 & 17.3 & 29 & 25.2 & \multirow{2}{*}{ Pearson Chi square $=1.75$, d. $f=1,0.186$} \\
\hline Informal & 153 & 78.1 & 67 & 82.7 & 86 & 74.8 & \\
\hline
\end{tabular}

The mean dmft of $7 ; 5 \pm 1.9 \mathrm{~d}$ was observed among children with Severe - ECC, and it ranged from 5 to 12 scores. Scores. However, the mean $\mathrm{dmft}$ for the males was $7.5 \pm 1.8$ and for females $(7.5 \pm 2.0)$, which was statistically insignificant difference found between the two groups $(\mathrm{t}=0.15, \mathrm{p}=0.88)$. The mean $\mathrm{dmft}$ score for children

aged three years was $6.9 \pm 2.2$, four years was $7.6 \pm 1.9$, and for five-year-olds was $7.2 \pm 1.2$ and all the $\mathrm{dmft}$ ranged from 5 - 12 . The dmft progressively increased with age and peaked at age four years. There were no statistically significant differences found between the age groups $(t=1.59, \mathrm{p}=0.248)$. Figure 1 .

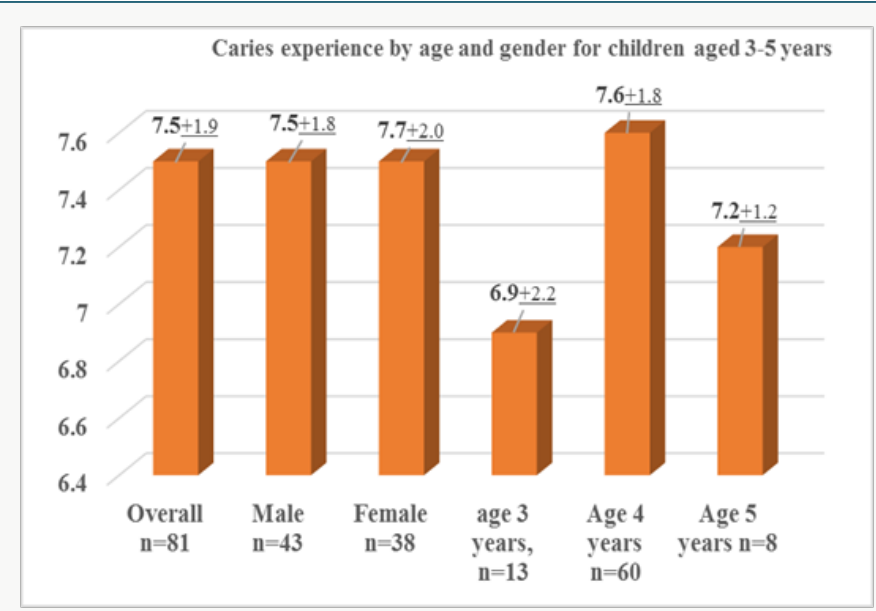

Figure 1: Distribution of decayed, missing, and filled teeth by age and gender. 
Overall the decayed component of the dmft contributed $92.3 \%$. The missing and filled component of the dmft contributed $7.4 \%$ and $0.3 \%$ respectively. The overall prevalence of underweight for acute malnutrition, stunting, and wasting for chronic malnutrition was $14.3 \%, 4.6 \%$, and $3.6 \%$ respectively. There were more females $17(17.7 \%), 4(4.2 \%)$, and $5(5.2 \%)$ who were underweight, wasted and stunted respectively when compared to males, but this difference was not statistically significant Pearson Chi-square respectively for underweight, stunted and wasted were $1.80, \mathrm{df}=1$, $\mathrm{p}=0.180 ; 0.19, \mathrm{~d} . \mathrm{f}=1, \mathrm{p}=0.660$ and 0.16 , d.f $=1, \mathrm{p}=0.686$ Figures 2 $\& 3$.

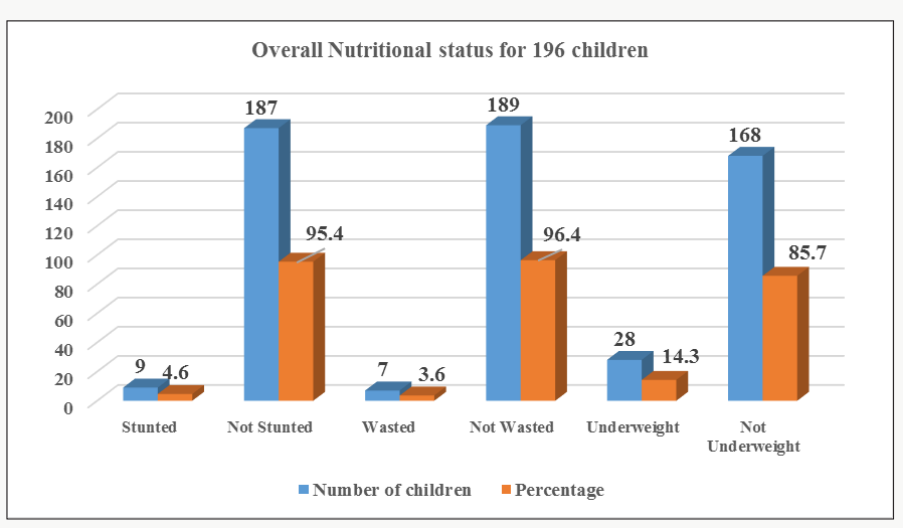

Figure 2: Prevalence of malnutrition for children aged 3-5 n=196.

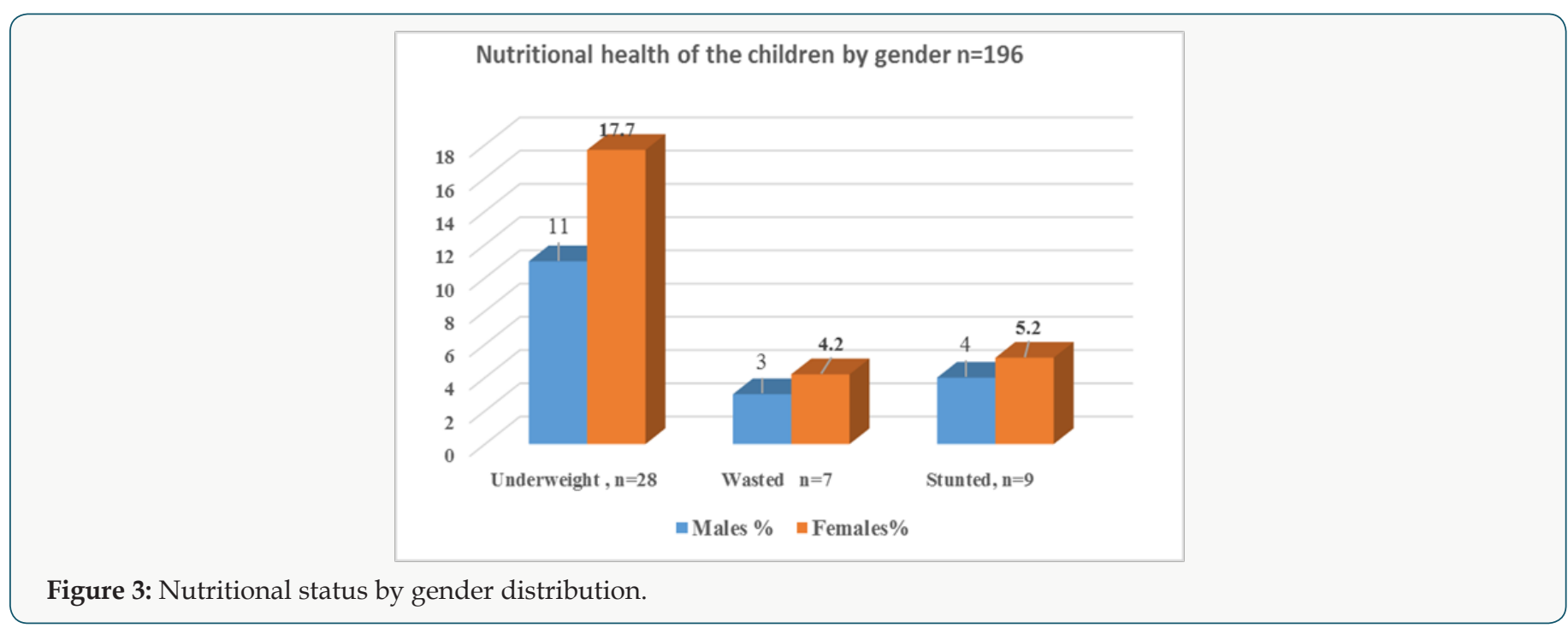

Table 3: Underweight among children with caregivers place residence, level of education, and occupation.

\begin{tabular}{|c|c|c|c|c|c|c|c|c|}
\hline \multirow{2}{*}{ Variables } & \multicolumn{2}{|c|}{ Underweight ( $n=28)$} & \multicolumn{2}{|c|}{ Normal weight $(n=168)$} & \multirow{2}{*}{ Odds Ratio } & \multicolumn{2}{|c|}{$95 \%$ CI } & \multirow{2}{*}{ P-value $\leq 0.05$} \\
\hline & $\mathbf{n}$ & $\%$ & $\mathbf{n}$ & $\%$ & & Lower & Upper & \\
\hline \multicolumn{9}{|c|}{ Caregivers area of residence } \\
\hline Rural & 10 & 15.4 & 55 & 84.6 & 1.14 & 0.50 & 2.63 & 0.757 \\
\hline Urban & 18 & 13.7 & 113 & 86.3 & 1 & & & \\
\hline \multicolumn{9}{|c|}{ Caregivers' Educational level } \\
\hline No formal education & 0 & 0.0 & 4 & 100.0 & UD & UD & UD & 0.999 \\
\hline Primary & 11 & 16.2 & 57 & 83.8 & 1.16 & 0.29 & 4.61 & 0.835 \\
\hline Secondary & 14 & 13.6 & 89 & 86.4 & 0.94 & 0.25 & 3.63 & 0.933 \\
\hline Higher & 3 & 14.3 & 18 & 85.7 & 1 & & & \\
\hline \multicolumn{9}{|c|}{ Occupation of the caregivers' } \\
\hline Employed Formal & 4 & 9.3 & 39 & 90.7 & 0.55 & 0.18 & 1.69 & 0.291 \\
\hline Self employed informally & 24 & 15.7 & 129 & 84.3 & 1 & & & \\
\hline
\end{tabular}

Citation: Dorah W, Gladys O, Mary M, Edith N, Regina M. The Nutritional Status of the Children with Severe-ECC Comparison with the Nutritional Status of Children without Caries Aged 3-5-Years-Old and with the Caregiver's Demographics in a Kenyan Hospital. Controlled Trial. Mod App Dent Oral Health 2(1)- 2018. 
When the caregiver's residence, level of education, and occupation were considered the children who lived in the rural areas had higher prevalences of were underweight $10(15.4 \%)$, when compared to the children in the urban areas $18(13.7 \%)$ resided in urban areas. Sixty-eight children had caregivers whose education was of a primary level, and $11(16.2 \%)$ of the children were underweight while 57 (83.8\%) had normal weight for age. Children whose parents had a secondary education were 103 of whom 14 (13.6\% were underweight, and $89(86,4 \%)$ had normal weight for an age while caregivers who had higher education were eighteen of whom 3(14.3\%) were underweight, and 15( $85.7 \%$ ) had normal weight. There were more underweight children $24(15,7)$ out of 153 when weight for age was examined about the caregivers who were informally employed, However, the differences in the children who were underweight with the caregiver's various demographics were not significant Table 3 .

According to the educational level, the children who were stunted and whose parents had a primary education were four $(9.3 \%))$, secondary $6(8.8 \%)$, and higher education were $5(7.7 \%)$. The caregivers who had formally employed were from the urban area while those who were informally employed and had primary school education were from the rural areas Table 4. There were statistically insignificant differences in the caregiver's place of residence, the level of education, and occupation among children who stunted and those who were not stunted.

Table 4: Stunting among children about caregivers place of residence, level of education, and occupation.

\begin{tabular}{|c|c|c|c|c|c|c|c|c|}
\hline \multirow{2}{*}{ Not stunted (n=187) } & \multicolumn{2}{|c|}{ Stunted $(n=9)$} & \multicolumn{2}{|c|}{ Not stunted $(n=187)$} & \multirow{2}{*}{ Odds ratio } & \multicolumn{2}{|c|}{$95 \%$ CI } & \multirow{2}{*}{$\mathrm{p} \leq \mathbf{0 . 0 5}$} \\
\hline & $\mathbf{n}$ & $\%$ & $\mathbf{n}$ & $\%$ & & Lower & Upper & \\
\hline \multicolumn{9}{|c|}{ Caregivers area of residence } \\
\hline Rural & 4 & 3.1 & 127 & 96.9 & 0.38 & 0.10 & 1.46 & 0.144 \\
\hline Urban & 5 & 7.7 & 60 & 92.3 & 1.00 & & & \\
\hline \multicolumn{9}{|c|}{ Caregivers' Educational level } \\
\hline Lacking formal education & 0 & 0.0 & 4 & 100.0 & UD & UD & UD & 0.999 \\
\hline Primary & 6 & 8.8 & 62 & 91.2 & 1.94 & 0.22 & 17.06 & 0.552 \\
\hline Secondary & 2 & 1.9 & 101 & 98.1 & 0.40 & 0.03 & 4.58 & 0.458 \\
\hline Higher & 1 & 4.8 & 20 & 95.2 & 1.00 & & & \\
\hline \multicolumn{9}{|c|}{ Occupation of the caregivers' } \\
\hline Employed Formal & 4 & 9.3 & 39 & 90.7 & 3.04 & 0.78 & 11.84 & 0.095 \\
\hline Self employed informally & 5 & 3.3 & 148 & 96.7 & 1.00 & & & \\
\hline
\end{tabular}

For the children who were wasted five $7.4 \%$ of the caregivers lived in the Urban area and had a primary level of education; also $6(3.9 \%)$ of the caregivers had informal employment, and $2(3.1 \%)$ differences in the caregiver's place of residence, the level of education, and occupation among children who wasted and those who were not wasted. resided in rural areas Table 5. There statistically insignificant

Table 5: Wasting among children about caregivers place of residence, level of education, and occupation.

\begin{tabular}{|c|c|c|c|c|c|c|c|c|}
\hline \multirow{2}{*}{ Variables } & \multicolumn{2}{|c|}{ Wasted $(n=7)$} & \multicolumn{2}{|c|}{ Not Wasted $(n=189)$} & \multirow{2}{*}{ Odds Ratio } & \multicolumn{2}{|c|}{$95 \%$ CI } & \multirow[t]{2}{*}{$\mathrm{p} \leq \mathbf{0 . 0 5}$} \\
\hline & $\mathbf{n}$ & $\%$ & $\mathbf{n}$ & $\%$ & & Lower & Upper & \\
\hline \multicolumn{9}{|c|}{ Place of residence } \\
\hline Urban & 5 & 3.8 & 126 & 96.2 & 1.25 & 0.24 & 6.62 & 0.793 \\
\hline Rural & 2 & 3.1 & 63 & 96.9 & 1.00 & & & \\
\hline \multicolumn{9}{|c|}{ Caregiver's level of education } \\
\hline No formal education & 0 & 0.0 & 4 & 100.0 & UD & UD & UD & 0.999 \\
\hline Primary education & 5 & 7.4 & 63 & 92.6 & 4.01 & 0.75 & 21.29 & 0.103 \\
\hline Secondary education & 2 & 1.9 & 101 & 98.1 & 1.00 & & & \\
\hline Higher education & 0 & 0.0 & 21 & 100.0 & UD & UD & UD & 0.999 \\
\hline \multicolumn{9}{|c|}{ Caregiver occupation } \\
\hline Formal & 1 & 2.3 & 42 & 97.7 & 0.58 & 0.07 & 4.98 & 0.618 \\
\hline Informal & 6 & 3.9 & 147 & 96.1 & 1.00 & & & \\
\hline
\end{tabular}

There was a slightly higher prevalence of underweight in the nutritional status of children with severe- ECC and children 14 '8\% for the children suffering from severe ECC compared with children without decay $13.9 \%$. Although there were differences without caries the differences were insignificant for stunting with $\mathrm{p}=0.311$; also underweight was insignificant with $\mathrm{p}=0.859$ while

Citation: Dorah W, Gladys O, Mary M, Edith N, Regina M. The Nutritional Status of the Children with Severe-ECC Comparison with the Nutritional Status of Children without Caries Aged 3-5-Years-Old and with the Caregiver's Demographics in a Kenyan Hospital. Controlled Trial. Mod App Dent Oral Health 2(1)- 2018. MADOHC.MS.ID.000130. DOI: 10.32474/MADOHC.2018.02.000130. 
wasting had $\mathrm{p}=0.451$ ). A child identified with Severe- ECC at risk 1.08 more times likely to become underweight when compared to a child who did not have decay odds ratio lower and upper limits of 0.48 and 2.4 at $95 \%$ CL Table 6.

Table 6: Comparison of the nutritional status of children with Severe ECC and children without caries.

\begin{tabular}{|c|c|c|c|c|c|c|c|c|}
\hline \multirow{2}{*}{ Variables } & \multicolumn{2}{|c|}{ Severe- ECC $(n=81)$} & \multicolumn{2}{|c|}{ Without caries $(n=115)$} & \multirow{2}{*}{ Odds Ratio } & \multicolumn{2}{|c|}{$95 \%$ CI } & \multirow{2}{*}{$\begin{array}{l}\text { Level of significance } p \\
\quad \leq 0.05\end{array}$} \\
\hline & $\mathbf{N}$ & $\%$ & $\mathbf{n}$ & $\%$ & & Lower & Upper & \\
\hline \multicolumn{9}{|c|}{ Stunting (HAZ) } \\
\hline Stunted & 2 & 2.5 & 7 & 6.1 & 0.39 & 0.08 & 1.93 & 0.311 \\
\hline Not Stunted & 79 & 97.5 & 108 & 93.9 & 1 & & & \\
\hline \multicolumn{9}{|c|}{ Wasted (WHZ) } \\
\hline Wasted & 4 & 4.9 & 3 & 2.6 & 1.94 & 0.42 & 8.91 & 0.451 \\
\hline Not Wasted & 77 & 95.1 & 112 & 97.4 & 1 & & & \\
\hline \multicolumn{9}{|c|}{ Underweight (WAZ) } \\
\hline Underweight & 12 & 14.8 & 16 & 13.9 & 1.08 & 0.48 & 2.42 & 0.859 \\
\hline $\begin{array}{c}\text { Not } \\
\text { Underweight }\end{array}$ & 69 & 85.2 & 99 & 86.1 & 1 & & & \\
\hline
\end{tabular}

Multivariate analysis was done to determine the relationship between underweight and Severe- ECC among the participating children. Five factors associated with underweight and SevereECC at $\mathrm{P} \leq 0.05$ during bivariate analysis were considered for multivariable analysis upon fitting the factors using binary logistic regression. Adjusting for child's age in years, child's oral hygiene status, child feeding on demand, place of residence and caregiver's level of education, the occurrence of S-ECC was not significantly associated with underweight (AOR=1.23; 95\% CI: 0.45 - 3.35; $\mathrm{p}=0.689$ ). However, a child with S - ECC was 1.23 times more likely to have low weight for an age when compared to a child who was caries - free. However adjusting for other factors, age three years was found to be statistically significantly associated with underweight with an Adjusted Odds Ratio value $=2.83$; $95 \%$ CI: 1.15 - 6.96; $\mathrm{p}=0.023$ Table 7. A child aged three years was 2.83 times more likely to be underweight when compared to one aged four years.

Table 7: Logistic Regression Predicting underweight using caries status, Child's age in years, Child's oral hygiene status, Child feeding on demand, Place of residence and Caregivers level of education.

\begin{tabular}{|c|c|c|c|c|}
\hline \multirow{2}{*}{ Variables } & \multirow{2}{*}{ Adjusted Odds Ratio } & \multicolumn{2}{|c|}{$95^{\wedge} \%$ Limit } & \multirow{2}{*}{$\begin{array}{c}\text { Level of significance } \\
\text { p-value }\end{array}$} \\
\hline & & Lower & Upper & \\
\hline \multicolumn{5}{|c|}{ Caries status } \\
\hline Severe-ECC & 1.23 & 0.45 & 3.35 & 0.689 \\
\hline Without caries & 1 & & & \\
\hline \multicolumn{5}{|c|}{ Child's age in years } \\
\hline Three years & 2.83 & 1.15 & 6.96 & 0.023 \\
\hline Four years & 1 & & & \\
\hline Five years & UD & UD & UD & 0.999 \\
\hline \multicolumn{5}{|c|}{ Child's oral hygiene status } \\
\hline Excellent & UD & UD & UD & 0.999 \\
\hline Good & 0.41 & 0.05 & 3.17 & 0.395 \\
\hline Fair & 0.69 & 0.13 & 3.70 & 0.661 \\
\hline Poor & 1 & & & \\
\hline \multicolumn{5}{|c|}{ A child fed on demand } \\
\hline Yes & 1.15 & 0.47 & 2.80 & 0.765 \\
\hline No & 1 & & & \\
\hline \multicolumn{5}{|c|}{ Place of residence } \\
\hline Rural & 0.87 & 0.36 & 2.12 & 0.763 \\
\hline Urban & 1 & & & \\
\hline \multicolumn{5}{|c|}{ Caregiver's level of education } \\
\hline
\end{tabular}

Citation: Dorah W, Gladys O, Mary M, Edith N, Regina M. The Nutritional Status of the Children with Severe-ECC Comparison with the Nutritional Status of Children without Caries Aged 3-5-Years-Old and with the Caregiver's Demographics in a Kenyan Hospital. Controlled Trial. Mod App Dent Oral Health 2(1)- 2018. 


\begin{tabular}{|c|c|c|c|c|}
\hline No Formal Education & UD & UD & UD & 0.999 \\
\hline Primary Education & 0.91 & 0.21 & 4.03 & 0.901 \\
\hline Secondary Education & 0.83 & 0.20 & 3.50 & 0.803 \\
\hline Higher Education & 1 & & & \\
\hline
\end{tabular}

\section{Discussion}

In the current study found that children with severe ECC were mainly from urban areas in comparison to children who were caries free. The finding of a high prevalence of severe -ECC in the urban children is similar to other studies in Kenya and elsewhere that have shown that children residing in urban areas have a higher caries experience than their rural counterparts $[4,5,11,12]$. The mean dmft of children with severe ECC in the present study was $7.5+1.9$ which is comparable to a study carried out among preschool children of low socioeconomic status in India which reported a mean dmft of 8.9 [13]. Studies in the USA, and Canada among preschool children found mean dmft scores of $9.6 \pm 3.6$ and 10.5 respectively [13-15]. The differences in the mean $\mathrm{dmft}$ may be due to variations in dietary practices among different populations. Also, decayed component accounted for $92.3 \%$ of the $\mathrm{dmft}$, and this finding was similar to a study in South Africa [14]. Untreated tooth decay reflects a low utilisation of oral health services or lack and inaccessibility of preventive and curative dental services to the caregivers, or if the facilities are available, they are too costly.

Higher caries experience was observed in the children from the urban areas when compared to their rural counterparts [11]. The mean dmft of children with severe ECC in the present study was $7.5+1.9$. The caries experience for severe-ECC in the present study is comparable to a study carried out in a low social, economic status in India among preschooler and reported a mean dmft of 8.9[112]. Studies in the USA, and Canada among preschool children have reported mean dmft scores of $9.6 \pm 3.6$ and 10.5 respectively $[13,14]$. The differences in the $\mathrm{dmft}$ could be due to variations in dietary practices among different populations. The decayed component in the current study accounted for $92.3 \%$ of the dmft, which similar to other studies elsewhere [14]. Untreated tooth decay reflects a low availability and accessibility of preventive and curative dental services.

In this study, there were more females were underweight, stunted, and wasted when compared to males when referenced on the WHO reference standard. However, the differences were insignificant. The WHO child growth standards reference was used to evaluate nutritional status. The WHO growth reference provides a scientifically reliable yardstick of children's growth achieved under desirable health and nutritional conditions and establishes the breastfed infant has been used as a reference against whom other alternative feeding practices are measured to and compare to regarding growth, health, and development of in children [9]. The children with severe-ECC who were underweight were $4.9 \%$, stunted $2.5 \%$, and those who were wasted were $14.8 \%$. The presence of underweight, stunting, and wasting may be associated with the inability of the children with severe-ECC to chew the available food and absorb enough nutrients resulting in faltering nutritional status. In comparison a study carried out in Italy among 2- 6 years old found that $11 \%$ were e underweight, $11.11 \%$ overweight and $22.2 \%$ to be at risk of overweight [15]. A study in the USA reporting on the BMI of children with severe ECC noted those who were underweight as $11 . \%$, overweight $11 \%$, and those who were at risk of overweight were nine $\% 6$. These findings were insignificant may be due to differences in cultural, dietary practices and the primary determinants of nutritional status among the different populations. In Kenya, the primary determinants of nutritional status among children under five years of age include poverty, hunger, and drought [16]. The low weight for age observed with urban children is similar to previous research from other countries where children with high prevalence with severe-ECC had low weight for age [17].

Children who were malnourished were also noted to have severe ECC compared to children who were caries free. There are high levels of malnutrition in Nyanza as reported in the Kenya Demographic and Health Survey 2008-2009 where 19\%, 2\%, and $14 \%$ of the children under five years were underweight, wasted and stunted respectively [18]. Considering the caregiver's demographic factors children who had low weight for age, wasting and stunted, resided in rural areas. Also, their caregivers had informal employment and had a primary level of education. The finding may be related to the low socioeconomic status and affect access to health care, food security and hence changing overall nutritional status $[16,17]$.

The differences in the nutritional status of the children with ECC and those without ECC was insignificant. South African children aged between four and five years reported similar findings as what has been observed in this study. Njoroge et al. reported $60 \%$ in a study population of 338 children aged five years and below[4]. The most affected dentition were the upper central incisors however the severity of decay increased with age and the first and the second deciduous molars had the highest prevalence ranging between $57 \%$ $-66 \%$. In this study, the caregivers knew the importance of good oral hygiene and significance of snacks about caries formation. However, the infant feeding habits and the weaning practices were not reported on in this study $[19,20]$.

The South African Study found no relationship between the prevalence stunting or wasting with dental caries. However, they reported an association between Wasting with the decayed, missing and filled tooth surfaces [7]. Children with severe ECC were 1.23 times more likely to be underweight when compared 
to children without caries. Severe ECC may affect general health and development because a toothache associated with caries may affect food intake and sleep [1]. Poor oral health associated with pain may interfere with the intake, mastication digestion of food and nutrients which may lead to decrease in good nutritional health and reduced quality of life for a child [1].

In summary, the difference in the nutritional status of children with severe ECC and children without caries and stunting was insignificant $\mathrm{p}=0.311$, Underweight $\mathrm{p}=0.859$ and wasting $\mathrm{p}=0.451$. However, children with Severe ECC were 1.23 .times more likely to be underweight than children without caries.

\section{References}

1. (2003) Definition of Early Childhood Caries (ECC). American Academy of Paediatric Dentistry.

2. Edelstein B (2006) The dental caries pandemic and disparities problem. BMC Oral health 6(1): S2.

3. ACS G, Shulmann R, Ng MW, Chussid S (1999) The effect of dental rehabilitation on the body weight of children with early childhood caries. Pediatr Dent 21(2):109-111.

4. Ngatia EM, Imungi JK, Muita JW, Nganga PM (2001) Dietary patterns and dental caries in nursery school children. East Africa Medical Journal 78(12): 673-677.

5. Njoroge N (2007) Early childhood caries among 3-5 year-olds and their caregiver's oral health knowledge, attitude and practice in Kiambaa Division, Kenya. The University of Nairobi Repository, Africa.

6. Sheller B, Churchill S, Williams BJ, Davidson B (2009) Body mass index of children with severe early childhood caries. Pediatric Dentistry 31(3): 216-221.

7. Cleaton Jones P (2000) Nutritional status and dental caries in a large sample of 4-and 5-year-old South African children. South African Journal of Clinical Nutrition 90(6): 631-635.
8. Hallet KB, O Rourke PK (2014) Pattern and severity of early childhood caries in Southern Italy: A preschool-based cross-sectional study. BMC public Health 14: 206

9. World health organisation (WHO) (2005) Physical status: The use and interpretation of anthropometry.

10. WHO (2013) Oral health surveys: Basic methods ( $5^{\text {th }}$ edn.), pp. 125.

11. Gaur S, Nayak R (2011) Underweight in low socioeconomic status preschool children with severe early childhood caries. J Indian Soc Pedod Prev Dent 29(4): 305-309.

12. Yi Li (2007) Genetic profiling of the oral Microbiota associated with severe early-childhood caries. J Clin Microbiol 45(1): 81-88

13. Schroth RJ, Moffatt ME (2005) Determinants of early childhood caries (ECC) in a rural Manitoba community: A pilot study. Pediatric Dentistry 27(2): 114-120.

14. Ismail AI, Lim S, Sohn W, Wilhelm JM (1996) The Determinants of early childhood caries in low-income African-young American children. Pediatric Dent 30(4): 289-296.

15. Vania A, Parisella V (2011) Early Childhood Caries underweight or overweight that is the question. Eur J Paediatr Dent 12(4): 231-235.

16. Oluoko Odingo, Alice Atieno (2006) Food security and poverty among small-scale farmers in Nyando District, Kenya. The University of Nairobi Repository, Africa.

17. Sam Loewenberg (2014) Breaking the cycle: of drought and hunger in Kenya. SL received grants from the Pulitzer Center on Crisis Reporting and the Nieman Foundation for Journalism at Harvard University for this report 383(9922): 1025-1028.

18. (2010) Kenya National Bureau of Statistics Kenya Demographic and Health Survey 2008-2009.

19. Ngatia EM, Imungi JK, Muita JW, Nganga PM (2001) Dietary patterns and dental caries in nursery school children. East Africa Medical Journal 78(12): 673-677.

20. Hallett K, O Rourke PK (2006) Pattern and severity of early childhood caries. Community Dent Oral Epidemiol 34(1): 25-35.
CC (P) This work is licensed under Creative Commons Attribution 4.0 License

To Submit Your Article Click Here: Submit Article

DOI: 10.32474/MADOHC.2018.02.000130

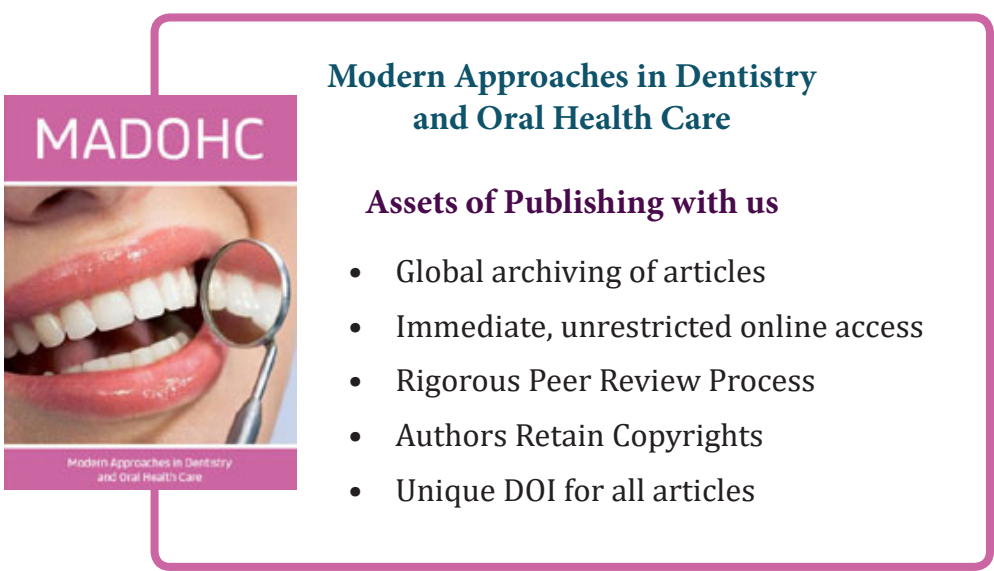

